\title{
Avaliação Longitudinal da Infecção por Parvovirus B19 entre Grávidas em Ribeirão Preto, SP, Brasil
}

\author{
Longitudinal Evaluation of Parvovirus B19 Infection among \\ Pregnant Women at Ribeirão Preto, SP, Brazil
}

\author{
Carla Vitola Gonçalves, Geraldo Duarte, Alessandra Cristina Marcolin \\ Silvana Maria Quintana, Dimas Tadeu Covas, Juvenal Soares Dias da Costa
}

\begin{abstract}
RESUMO
Objetivos: avaliar a taxa de soroprevalência contra o parvovírus B19 (PB19) entre grávidas e a taxa de soroconversão dessa infecção durante a gravidez.

Métodos: estudo prospectivo realizado no Hospital das Clinicas da Faculdade de Medicina de Ribeirão Preto da Universidade de São Paulo. Na primeira fase do estudo foram avaliadas 245 grávidas com idade gestacional menor que 16 semanas, para aferição da soroprevalência da infecção PB19, utilizando o método ELISA. De acordo com os resultados sorológicos, classificou-se a infecção pelo PB19 em aguda (IgM positivo e Ig G negativo ou positivo) ou remota (IgM negativo e IgG positivo). Na segunda fase do estudo, 73 grávidas soronegativas foram novamente testadas durante a internação para o parto (IgM e IgG), objetivando aferir a taxa de soroconversão durante a gravidez.

Resultados: a prevalência da infecção PB19 até a $16^{a}$ semana de gravidez foi de $62,9 \%$ (IC 95\%: 56,8-68,9), divididas em infecção aguda (8,1\%) e remota (54,8\%). Das 73 grávidas soronegativas que submeteram-se a novo teste no momento do parto, sete (9,6\%) apresentaram soroconversão durante a gravidez (IC 95\%: 2, 8-16,3), sendo duas com infecção aguda (2,7\%) e cinco com infecção remota (6,9\%). A prevalência final da infecção por PB19 durante a gravidez foi de $72,5 \%$.

Conclusões: considerando que apenas a infecção aguda pelo PB19 está associada a risco de transmissão vertical, a soroprevalência relativamente alta desta infecção entre grávidas estaria protegendo os fetos contra esta forma de disseminação do virus. Apesar da elevada taxa de soroconversão para PB19 durante a gravidez, não foi observado nenhum caso de infecção sintomática entre os recém-nascidos.
\end{abstract}

PALAVRAS-CHAVE: Infecções na gravidez. Parvovírus B19. Transmissão vertical.

\section{Introdução}

O parvovirus B19 (PB19) foi detectado acidentalmente por Cossart et al. ${ }^{1}$ em 1975 , como novo antígeno encontrado no soro de doadores

Setor de Moléstias Infecto-Contagiosas em Ginecologia e Obstetrícia do Departamento de Ginecologia e Obstetrícia da Faculdade de Medicina de Ribeirão Preto da Universidade de São Paulo

Correspondência:

Geraldo Duarte

Avenida Bandeirantes, 3900

Hospital das Clínicas da Faculdade de Medicina de Ribeirão Preto - USP

14049-900 - Ribeirão Preto - SP

Fone: (016) 602-2588

e-mail: gduarte@fmrp.usp.br de sangue cujas amostras estavam sendo submetidas a testes sorológicos para o diagnóstico do virus da hepatite B. Classicamente, o quadro clínico dessa infecção associa-se a crises aplásticas de medula, eritema infeccioso, mialgia, artralgia e febre. Já está bem estabelecido que o principal modo de transmissão do PB19 entre humanos é o contacto direto pessoa/pessoa por meio de perdigotos e partículas aerossolizadas respiratórias ${ }^{2}$.

Em 1984 foi relatado o primeiro caso de infecção intra-útero por PB19, com hidropisia fetal ocorrida durante uma epidemia de eritema infeccioso. Com esse relato, documentou-se a potencial histotoxicidade do PB19 aos tecidos embrionários e fetais, agregando mais essa compli- 
cação ao grupo das doenças associadas ao $\mathrm{PB} 19^{3}$. $\mathrm{Na}$ transmissão vertical, o vírus PB19 ultrapassa a barreira placentária e entra na circulação fetal, acometendo as células progenitoras dos eritrócitos, nas quais ocorre a replicação viral. A destruição dessas células pelo PB19 durante o período de viremia provoca grave redução numérica das hemácias e da concentração da hemoglobina fetal. Se a infecção ocorrer entre a $10^{a}$ e a $20^{a}$ semana de gravidez, os efeitos fetais são mais graves, visto que a resposta imune fetal ainda não é capaz de controlar a infecção e esta coincide com intensa atividade metabólica dos precursores eritróides, situação em que o PB19 destrói o maior número de células, aumentando a taxa de abortamentos ${ }^{4,5}$.

Nas infecções fetais por PB19 que ocorrem na segunda metade da gravidez, o declínio da concentração de hemoglobina fetal resulta em anemia com falência cardíaca levando à hidropisia fetal ${ }^{6,7}$. Alguns autores referem a hidropisia fetal como sendo o quadro clínico mais importante em fetos infectados pelo PB19, sendo esta, felizmente, complicação de baixa freqüência. O PB19 foi identificado como o fator etiológico em taxas que variam de 10 a $27 \%$ dos casos de hidropisias não imunitárias ${ }^{5,8}$.

$\mathrm{O}$ exame mais apropriado para identificar hidropisia fetal, sinal mais freqüente de comprometimento fetal pelo vírus B19, é a ultrasonografia ${ }^{9}$. No entanto, a confirmação da infecção fetal por esse virus só é possível por meio de técnicas de biologia molecular, sobressaindo-se a reação em cadeia da polimerase (polymerase chain reaction, PCR) do líquido amniótico, do sangue do cordão umbilical e do derrame pleural, nos casos de hidropisia grave $e^{9,10}$.

Quanto ao tratamento da infecção fetal pelo PB19, os trabalhos são controversos. Há relatos demonstrando que a transfusão sangüinea intraútero, intra-peritoneal ou por cordocentese é o tratamento de escolha para hidropisia e/ou anemia fetal causadas pela infecção pelo PB19 $9^{11,12}$. Outros autores relatam que a espera pela cura espontânea seria a medida mais correta, com maior chance de resolução do caso e menores riscos para o feto ${ }^{13}$.

Sabendo-se que a transmissão vertical do PB19 é possível somente quando o primeiro contato da grávida com o vírus ocorre durante o período gestacional ${ }^{3,4}$, questiona-se a validade de aferição da taxa de soroconversão para esta virose durante a gravidez em nossa população.

Como não existe nenhum estudo nacional sobre a taxa de soroprevalência do PB19 em grávidas e nem avaliações sobre a taxa de soroconversão neste período, achamos adequada a proposição do presente estudo, que foi avaliar a taxa de soroprevalência contra o PB19 entre grávidas e a taxa de soroconversão dessa infecção durante a gravidez.

\section{Pacientes e Métodos}

Estudo prospectivo avaliando grávidas atendidas no Hospital das Clínicas da Faculdade de Medicina de Ribeirão Preto da Universidade de São Paulo (HC-FMRPUSP) e no Centro de Saúde Escola da FMRPUSP, uma Unidade de Atendimento Secundário do Sistema Único de Saúde do município de Ribeirão Preto. Os aspectos éticos deste estudo foram avaliados e aprovados pelo Comitê de Ética do HC-FMRPUSP.

$\mathrm{Na}$ primeira fase do estudo foram obtidas amostras sangüíneas de 245 grávidas com idade gestacional menor que 16 semanas, para aferição da soroprevalência da infecção por PB19 (IgM e IgG), utilizando o método ELISA. De acordo com os resultados da sorologia, classificouse a infecção por PB19 em aguda (IgM positivo e IgG negativo ou positivo) ou remota (IgM negativo e IgG positivo). As grávidas identificadas como não sensibilizadas contra o PB19 (IgG negativo e IgM negativo) formaram o grupo que foi avaliado posteriormente para aferir a taxa de soroconversão contra este virus durante a gravidez. Portanto, a segunda fase do estudo consistiu de avaliação prospectiva, obtendo-se as amostras sangüíneas durante a internação para o parto de 73 pacientes que eram soronegativas na primeira avaliação. O estadiamento sorológico da infecção seguiu os mesmos critérios utilizados para a primeira fase do estudo. Houve perda de 18 pacientes da primeira para a segunda fase do estudo (parto em outros hospitais).

As amostras sanguíneas foram colhidas utilizando punção intravenosa periférica de um dos membros superiores da paciente. Após centrifugação das amostras para separação do soro, as amostras séricas foram congeladas a $-20^{\circ} \mathrm{C}$. A detecção qualitativa e quantitativa de IgG e IgM contra o PB19 foi realizada utilizando testes imunoenzimáticos (ELISA anti-PB19 IgG e IgM), da MRL Diagnostics (Califórnia, USA), distribuídos pela REM Indústria e Comércio Ltda. Quanto às características do desempenho dos testes, a informação do fabricante indicava sensibilidade e especificidade para IgG de 96 e $97 \%$, respectivamente. Para detecção de IgM, a sensibilidade informada foi de $89 \%$ e a especificidade de $98 \%$.

Os procedimentos técnicos para realização do teste ELISA, a avaliação dos resultados e o controle de qualidade dos experimentos seguiram 
as orientações do fabricante. Os resultados foram classificados de acordo com o valor índice (VI), sendo considerados positivos quando o VI foi maior que 1,20 , negativos quando o VI foi menor que $0,80 \mathrm{e}$ inconclusivos quando o VI ficou entre 0,80 e 1,20. Nesses casos as amostras foram retestadas, conforme orientação do fabricante. Para o controle de qualidade dos ensaios considerou-se o VI do controle positivo maior que 1,5 . Por sua vez, o VI do controle negativo foi considerado para valores menores que 0,8 . Nos casos em que o calibrador e os controles não estiveram nesta faixa de variação, os resultados da placa foram considerados inválidos e os ensaios repetidos.

Na primeira fase do estudo, foram calculadas as razões de prevalência (infecção aguda, recente e remota) e seus respectivos intervalos de confiança (IC 95\%). Na segunda fase foram calculadas as razões de prevalência e de incidência e os respectivos intervalos de confiança das duas variáveis.

\section{Resultados}

Das 245 pacientes testadas na primeira fase do estudo, 154 apresentavam infecção remota ou aguda por PB19, com prevalência de $62,9 \%$ (IC 95\%: 56,8-68,9). Das 154 pacientes infectadas, 134 apresentavam marcadores sorológicos para infecção remota (IgG positiva e IgM negativa), 11 apresentavam IgG e IgM positivos, e em nove, a IgG foi negativa e a IgM positiva. Esses dois últimos grupos indicam infecção aguda por PB19, representando $8,1 \%$ da amostra (Figura 1). As outras $91(37,1 \%)$ pacientes não apresentavam marcadores sorológicos indicativos de infecção pregressa ou aguda pelo PB19, apresentando IgG e IgM negativos.

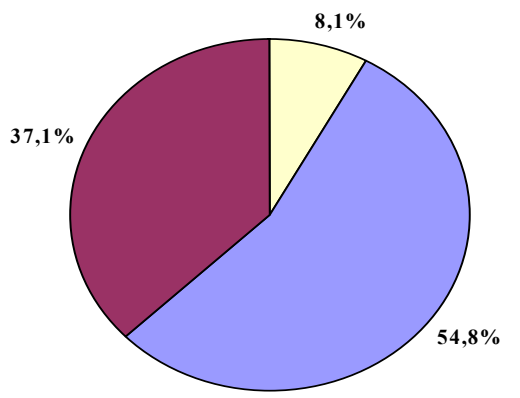

$\square$ Infecção aguda $\square$ Infecção pregressa $\square$ Não infectadas

Figura 1 - Distribuição das pacientes com infecção aguda, infecção remota e não infectadas pelo PB19, em gestantes com até 16 semanas de gestação (Ribeirão Preto, SP, Brasil).

Das 91 pacientes que não apresentavam marcadores sorológicos de infecção aguda ou pregressa pelo PB19, 18 deram à luz em outros hos- pitais e foram retiradas da casuística. Das 73 $(80,2 \%)$ que foram testadas para essa infecção após o parto, sete sofreram soroconversão no período gestacional, representando incidência de $9,6 \%$ (IC 95\%: 2,8-16,3), e $66(90,4 \%)$ pacientes permaneceram com sorologias negativas para o PB19. Entre as sete pacientes que apresentaram soroconversão, duas tinham sorologia compativel com infecção aguda (IgG negativo e IgM positivo) e cinco apresentavam marcadores de soroconversão ocorrida há mais de três meses (IgG positivo e IgM negativo). Portanto, a prevalência de infecção pelo PB19 no final da gravidez foi de $72,5 \%$, com $27,5 \%$ de grávidas soronegativas, ainda suscetiveis à infecção por este virus (Figura 2).

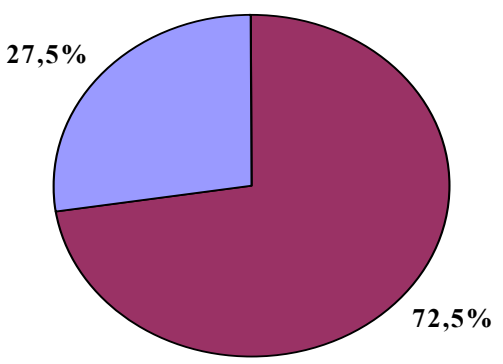

$\square$ Positivas

$\square$ Negativas

Figura 2 - Prevalência da infecção pelo PB19 em gestantes avaliadas no final da gestação (Ribeirão Preto, SP, Brasil).

\section{Discussão}

A primo-infecção pelo PB19 durante a gravidez tem sido associada a várias complicações fetais, sobressaindo-se aborto, anemia e conseqüente hidropisia fetal, restrição de crescimento intra-útero e morte fetal. Avaliando 113 grávidas com evidência sorológica de infecção por PB19, Rodis et al. ${ }^{14}$ observaram quatro casos de abortamento espontâneo e um caso de hidropisia fetal, demonstrando a importância da transmissão vertical desse vírus.

Os relatos da literatura indicam que em 10 a $27 \%$ dos casos de hidropisia fetal não imune, com estudo morfológico normal, a infecção pelo PB19 é a responsável por essa complicação $^{4,10}$. Utilizando a PCR, Jordan ${ }^{15}$ detectou o DNA do PB19 em 18\% dos casos de hidropisia fetal não imune.

Segundo dados da literatura, se a contaminação fetal ocorrer até a $20^{\mathrm{a}}$ semana de gravidez o risco de morte fetal chega a 9\%. Ocorrendo a infecção no último trimestre, a morte fetal atinge a cifra de $7,5 \%^{16,17}$. Diante dessas evidências realizou-se o presente estudo, visando avaliar a prevalência dessa infecção em grávidas na cidade de Ribeirão Preto e sua incidência (taxa de soroconversão) durante o período gestacional. 
No presente trabalho, a prevalência da infecção pelo $\mathrm{PB} 19^{18}$ até a $16^{\mathrm{a}}$ semana de gravidez foi de $62,9 \%$. Segundo o CDC, aproximadamente $50 \%$ das grávidas já estão imunes ao PB19 e, conseqüentemente, essas mulheres e seus fetos estariam protegidos de infecções futuras. Em trabalho realizado no Brasil, na cidade de Belém, a soroprevalência da infecção pregressa por PB19 entre grávidas foi de $84,3 \%$, percentuais mais elevados que os $62,7 \%$ encontrados na presente casuística. Por outro lado, a prevalência de infecção aguda foi de $1,7 \%$ no estudo de Belém e de $8,2 \%$ no presente estudo, demonstrando a importância dos estudos regionais para obtenção dos dados sorológicos de cada comunidade ${ }^{19}$. Em trabalho realizado na Dinamarca, observou-se que $65 \%$ das grávidas apresentaram evidências séricas de infecção prévia por PB1920, números bem próximos dos $66 \%$ encontrados por Jensen et al. ${ }^{21}$, também na Dinamarca. A investigação da soroprevalência do PB19 em diferentes populações na África mostrou que 56 a 91\% das grávidas apresentavam anticorpos contra o vírus PB19. A ampla variação dos resultados dessa soroprevalência foi atribuída ao fato de que eles dependem do grupo populacional ao qual a grávida pertencia ${ }^{22}$.

A taxa de soroconversão para PB19 durante a gravidez observada nesta casuística foi de $9,6 \%$ (IC 95\%: 2,8-16,3). Em estudo realizado por Gratacós et $a .^{4}$, a incidência de infecção aguda durante a gravidez foi de 3,7\% (60/1610), observando-se que a taxa de perda fetal entre essas pacientes foi de $1,7 \%(1 / 60)$. Segundo Harger et al. ${ }^{23}$, o risco relativo de infecção materna seria de 2,8\% (IC 95\%: 1,7-4,6). No Brasil, em estudo realizado na cidade de Belém ${ }^{19}$, a taxa de soroconversão durante a gravidez foi de $1,7 \%$. Para ValeurJensen et $a .^{20}$, as taxas de soroconversão anuais em mulheres suscetiveis à infecção por PB19 são dependentes das estações do ano e de eventuais períodos endêmicos. Nos meses de verão, a incidência seria de 1,5\% (IC 95\%: 0,2-1,9). Por outro lado, no período epidêmico (considerando os meses de inverno) a taxa de soroconversão seria de 13\% (IC 95\%: 8,7-23,1). No total, para esses autores, a taxa média anual de soroconversão para infecção por PB19 entre as grávidas foi de 2,4\%.

A taxa de soroconversão de $9,6 \%$ para o PB19 encontrada no presente estudo está entre as taxas de 1,7 e $13,0 \%$ referidas na literatura ${ }^{20,21}$. Porém, não se observou nenhum incremento que pudesse ser associado aos meses correspondentes ao inverno. O fato de não se encontrar maior taxa de soroconversão no inverno pode ser explicado pelo clima subtropical da região de Ribeirão Preto, dificultando uma divisão clara entre as estações do ano.
Atualmente, a melhor classificação para o clima é a de Köppen, que leva em conta fatores como relevo, regime de chuvas e temperatura nas diversas estações do ano. Segundo essa classificação, a região de Ribeirão Preto apresenta clima subtropical, com média de temperatura de $24^{\circ} \mathrm{C}$ nos meses de verão e, durante os meses mais frios, de $15^{\circ} \mathrm{C}$. A média anual de temperatura é de $22^{\circ} \mathrm{C}$. Sendo assim, acredita-se que a cidade de Ribeirão Preto não apresenta diferenças de temperatura durante o ano que permitam a divisão de período endêmico e epidêmico para o estudo da infecção por PB1924.

Fazendo projeção para aplicação prática dos resultados deste trabalho, devem ser salientados dois pontos. O primeiro é que, apesar do expressivo percentual de soroconversão contra o PB19, não houve nenhum feto ou recém-nascido acometido clinicamente, indicando que não há indicação rotineira deste exame durante o prénatal. O outro ponto diz respeito à possibilidade de que estes fetos sejam acometidos por esta infecção, alertando o pré-natalista de que todos os casos de hidropisia fetal não imune devem, obrigatoriamente, ser avaliados com a inclusão da infecção fetal pelo PB19 no diagnóstico diferencial. Estas conclusões práticas são convergentes com aquelas divulgadas por estudos que avaliaram a necessidade de inclusão do teste sorológico para detecção das grávidas suscetíveis à infecção aguda por PB19 entre os exames de rotina no pré-natal, concordando que esta intervenção não apresenta relação custo-beneficio favorável ${ }^{23,25}$.

\section{Abstract}

Purpose: to evaluate the rate of seropositivity for parvovirus B19 (PB19) among pregnant women and the rate of seroconversion against this infection during pregnancy.

Methods: prospective study carried out in the Hospital of the Medical School of Ribeirão Preto, University of São Paulo. In the first stage of the present study, we evaluated 245 pregnant women with gestational age less than 16 weeks to determine the seroprevalence of PB19 infection by ELISA. According to the serological results we determined if the PB19 infection was an acute infection (IgM positive and $\operatorname{Ig} G$ negative or positive), or a former infection (IgM negative and $\operatorname{IgG}$ positive). In the second stage of this study, 73 previously seronegative pregnant women were tested again when they came to the hospital for delivery (IgM and $\operatorname{IgG}$ ), to detect the seroconversion rate during pregnancy.

Results: the seroprevalence of the PB19 infection until 16 weeks of gestation was $62.9 \%$ (95\% IC: $56.8-68.9$ ), divided 
into acute infection (8.1\%), or former infection (54.8\%). Of the 73 patients, seronegative in the first stage of this investigation, seven (9.6\%) showed seroconversion during pregnancy (95\% IC: 2.8-16.3), two (2.7\%) showed acute serological infection and five (6.9\%) presented markers of past infection. The final seroprevalence of PB 19 infection during pregnancy was $72.5 \%$.

Conclusions: considering that only the acute PB 19 infection is associated with risk for vertical transmission, the high seroprevalence of this infection observed in this study would be protecting these fetuses against this form of infection. Despite the relatively high rate of seroconversion against PB19 infection during the pregnancy period, we did not observe any symptomatic neonate in this group.

KEYWORDS: Infections during pregnancy. Parvovirus B19. Vertical transmission.

\section{Referências}

1. Cossart YE, Field AM, Cant B, Widdows D. Parvoviruslike particles in human sera. Lancet 1975; 11:72-3.

2. Portmore AC. Parvoviruses (erythema infectiosum, aplastic crisis). In: Mandell GL, Bennett JE, Raphael D, editors. Principles and Practice of Infections Diseases. $4^{\text {th }}$ ed. Philadelphia: Churchill Livingstone; 1995. p.1439-44.

3. Brown T, Anand A, Ritchie LD, Clewley JP, Reid TM. Intrauterine parvovirus infection associated with hydrops fetalis. Lancet 1984; 2:1033-4.

4. Gratacós E, Torres PJ, Vidal J, et al. The incidence of human parvovirus B19 infection during pregnancy and its impact on perinatal outcome. J Infect Dis $1995 ; 171: 1360-3$.

5. Kailasam C, Brennand J, Cameron AD. Congenital parvovirus B19 infection: experience of a recent epidemic. Fetal Diagn Ther 2001; 16:18-22.

6. Public Health Laboratory Service Working Party on Fifth Disease. Prospective study of human parvovirus B19 infection in pregnancy. BMJ 1990; 300:1166-70.

7. Mustafa MM, McClain KL. Diverse hematologic effects of parvovirus B19 infection. Pediatr Clin North Am 1996; 43:809-21.

8. Morey AL., Keeling JW, Porter HJ, Fleming KA. Clinical and histopathological features of parvovirus B19 infection in the human fetus. Br J Obstet Gynaecol 1992; 99:566-74.

9.Musiani M, Pasini P, Zerbini M, et al. Prenatal diagnosis of parvovirus B19 induced hydrops fetalis by chemiluminescence in situ hybridization. J Clin Microbiol 1999; 37:1326-9.

10.Jordan JA, DeLoia JA. Globoside expression within the human placenta. Placenta 1999; 20:103-8.

11.Rodis JF, Borgida AF, Wilson M, et al. Management of parvovirus infection in pregnancy and outcomes of hydrops: a survey of members of the Society of
Perinatal Obstetricians. Am J Obstet Gynecol 1998; 179:985-8.

12.Dembinsk J, Haverkamp F, Maara H, Hansmann M, Eis-Hubinger AM, Bartmann P. Neurodevelopmental outcome after intrauterine red cell transfusion for parvovirus B19-induced fetal hydrops. BJOG 2002; 109:1232-4.

13. Forestier F, Tissot JD, Vial Y, Daffos F, Hohlfeld P. Haematological parameters of parvovirus B19 infection in 13 fetus with hydrops foetalis. $\mathrm{Br} \mathrm{J}$ Haematol 1999; 104:925-7.

14. Rodis JF, Rodner C, Hansen AA, Borgida AF, Deoliveira I, Sulman Rosengren S. Long-term outcome of children following maternal human parvovirus B19 infection. Obstet Gynecol 1998; 91:125-8.

15.Jordan JA. Identification of human parvovirus B19 infection in idiopathic nonimmune hydrops fetalis. Am J Obstet Gynecol 1996; 174:37-42.

16. Miller E, Fairley CK, Cohen BJ, Seng C. Immediate and long term outcome of human parvovirus B19 infection in pregnancy. Br J Obstet Gynaecol 1998; 105:174-8.

17.Skjöldebrand-Sparre L, Tolfvenstam T, Papadogiannakis $\mathrm{N}$, Wahren $\mathrm{B}$, Broliden $\mathrm{K}$, Nyman $\mathrm{M}$. Parvovirus B19 infection: association with thirdtrimester intrauterine fetal death. BJOG 2000; $107: 476-80$

18.Centers For Disease Control And Prevention. Fifth disease \& parvovirus B19 infection. [serial online] 1999 Mar [cited 2002 Mar 20]. Available from: URL: http: / / www.cdc.gov./ncidod/dissease / parvob19.htm.

19.Barros de Freitas R, Buarque de Gusmão SR, Durigon EL, Linhares AC. Survey of parvovirus B19 infection in a corhort of pregnant women in Belém, Brazil. Braz J Infect Dis 1999; 3:6-14.

20.Valeur-Jensen AK, Pedersen CB, Westergaard T, et al. Risk factors for parvovirus B19 infection in pregnancy. JAMA 1999; 281:1099-105.

21.Jensen IP, Thorsen P, Jeune B, Moller BR, Vestergaard BF. An epidemic of parvovirus B19 in a population of 3,596 pregnant women: a study of sociodemographic and medical risk factores. BJOG 2000; 107:637-43.

22.Tolfvenstam T, Enbom M, Ghebrekidan H, et al. Seroprevalence of viral childhood infections in Eritrea. J Clin Virol 2000; 16:49-54.

23. Harger JH, Adler SP, Koch WC, Harger GF. Prospective evolution of 618 pregnant women exposed to parvovirus B19: risks and symptoms. Obstet Gynecol 1998; 91:413-20.

24.Instituto Nacional de Metereologia. Climatologia [cited 2001 Set 9]. Available from: URL:http:// www.inmet.gov.br.

25.Fean WS, Yee CF, Cincotta RB, Tilse M. Human parvovirus B19 infection in pregnancy: should screening be offered to the low-risk population? Aust N Z J Obstet Gynaecol 2002; 42:347-51.

Recebido em: 22/5/2003

Aceito com modificações em: 9/6/2003 